\title{
Enhancing Student Disclosure: Australia's Invisible Equity Students and Reasons for Nondisclosure in Australia's Tertiary Sector
}

\author{
Colin Clark \\ Rita Kusevskis-Hayes \\ Matthew Wilkinson
}

The University of New South Wales

\begin{abstract}
Many students in tertiary institutions who are eligible for equity consideration and accommodations decide not to disclose their equity status. Discussions of equity disclosure concern fears of stigma, questions of purpose, and the relationship between visibility of equity status and disclosure. This paper reports on the concept of self-disclosure of equity group membership at university. This study is the result of an investigation of the factors that encourage domestic students from identified equity groups to self-disclose this information to higher education providers.
\end{abstract}

The project considers three key equity groups:

- Students with disabilities

- Indigenous students

- Domestic students from non-English speaking backgrounds (NESB)

An understanding of nondisclosure would inform future policy and program design to encourage disclosure of hidden subpopulations with specific needs. In this article, we review the literature on disclosure, considering common themes and discussions around these three equity groups. We report on preliminary findings from a survey of university equity service staff on their perceptions of reasons for nondisclosure. When the study is complete, with student surveys and interview/focus group data, the information will be used to generate guidelines to help universities plan equity support measures, allocate appropriate resources and train staff.

Keywords: Australia; Disability; Disclosure; Equity; Indigenous; Non-English-Speaking; Tertiary

\section{Disclosure in the literature}

Many students entering tertiary institutions in Australia do so in the face of significant challenges and obstacles to their success and wellbeing. Such students include those with disabilities, those from traditionally disadvantaged groups such as Indigenous communities, those who speak English as a second language, or those from low socio-economic status backgrounds. Equity services are in place in many institutions to "level the playing field", offering accommodations in study and student life to overcome many limitations that these circumstances present. These accommodations are critical for creating a fair and equitable environment, and for ensuring that students can achieve their goals and reach their potential, notwithstanding their challenges.

Despite the role of equity services in helping students to overcome limitations related to equity status, many eligible students decide not to disclose their status. This tendency may prevent students from accessing targeted support to which they are entitled, or hamper effective intervention when support is required. The reasons for this lack of self-disclosure are complex. Although research is increasingly focused on the circumstances that surround self-disclosure, much continues to be personal accounts (see Jacklin, 2011), with a small but growing qualitative literature (Bulk, 2014; Cox et al., 2017; Hernandez, 2011; Riley \& Hagger, 2015; Rosenthal, Efklides, \& Demetriou, 1988; Sung, Lin, Connor, \& Chan, 2017). There is a growing focus on self-disclosure in relation to disabilities, which has encouraged discussion of hidden/visible disabilities and disclosure, stigma, and the utility of 
disclosing a disability (Bulk, 2014; Kreider, Bendixen, \& Lutz, 2015; Mathews \& Harrington, 2000; Mullins \& Preyde, 2013). There is also much discussion of Indigenous status and self-disclosure, both in Australia and globally (Bandias, Fuller, \& Larkin, 2014; Chirgwin, 2015; DiGregorio, Farrington, \& Page, 2000; Farrington \& Daniel DiGregorio, n.d.; Rochecouste et al., 2016). There is smaller body of literature on nondisclosure of equity status among students who have learned English as a second language, or come from a non-English speaking background (Earnest, Joyce, de Mori, \& Silvagni, 2010; Hannah, 1999; Joyce, Earnest, de Mori, \& Silvagni, 2010; Kong et al., 2016). This literature review critically discusses disclosure and nondisclosure among these three groups, focusing on theories of nondisclosure. This is followed by a discussion of methodologies utilized in equity disclosure research and the methodological challenges of studying non-disclosing populations - a "hidden" demographic.

\section{Disability and disclosure}

In 2015, the Australian tertiary sector included a population of 1,035,474 students. Of these, 60,019, or approximately 5.8\%, identify as having a disability (Department of Education and Training, 2016). This indicates a $7.9 \%$ increase in the number of students with disabilities since 2014 . However, these figures may not be representative of the entire population of students with disabilities. Despite strides made in framing and conceptualizing disabilities, and a growing population of tertiary students with disabilities, many students choose not to disclose their disability to university services. They do not disclose formally, or they selectively disclose to friends and confidantes, or keep their disability hidden altogether. In some cases, students may have disclosed to other institutions, such as the Australian Bureau of Statistics (ABS) or to other disability services, but not to the university itself. This may have outcomes that affect students' wellbeing and the university's services, resourcing, and institutions.

The decision not to disclose is influenced not merely by institutional issues, but by social factors as well. Stigma is one of the most widely discussed and attributed reasons for nondisclosure (HartmanHall \& Haaga, 2002; Hoehn, 1998), and is a fundamental consideration for individuals with disabilities. However, not all disabilities are associated with stigma in the same way. Disabilities that are highly visible, such as ambulatory impediments (being wheelchair-bound) and other physical impediments, owing to their high visibility, are less likely to attract stigma.

"Hidden" disabilities, on the other hand, including cognitive and mental disabilities, are associated with higher rates of stigma (Hernandez 2011). Jacklin (2011) found that self-disclosure was more likely in cases where it was impossible to hide a disability. In Jacklin's (2011) case study, this involved a student prone to suffering seizures, a condition that is sometimes hidden and other times highly visible. However, this did not extend to formal disclosure. Rather, in Jacklin's (2011) case, she disclosed informally to friends and colleagues, but feared formal disclosure to an institution would limit her opportunities in the future, a finding supported by the fact that the only institution accepting Jacklin for post-graduate study was the only one to which she did not disclose her disability.

Morris and Turnbull (2006) found that disclosure of a hidden disability — dyslexia — by nursing students involved significant considerations of stigma. For these students, disclosure involved a number of stigma-related considerations: peer attitudes, career outcomes, and pity. Some students associated disclosure with admissions that a problem existed, and shame. Regarding dyslexia, one such student in the study stated "no one knows about it-I can't bring myself to say it. I hated to be labelled as having it (dyslexia). I just can't and I hate it" (2006, p. 242). Likewise, Olney and Brockelman (2003) found that students with less visible disabilities were concerned that others would not believe they had a bona fide disability; they felt that others would see them as less competent, and worried about being seen as needing help rather than a peer who could give and take in relationships (2003, p. 48). Overall, Olney and Brockerman (2003) found that disclosure involves an 
“intricate decision-making process about revealing disability information”.

Riley and Hagger (2015) interviewed 10 people of various ages who had suffered from a traumatic brain injury. They identify six reasons for nondisclosure: fears of negative reactions from others, feelings of shame, avoidance of emotional upset about the incident causing the injury, feelings that others were not interested in their injury, perceptions that the stress of disclosing their injury to others outweighed the benefits and a desire to fit in as a person without a brain injury-or in other words, not wanting a traumatic brain injury to define them and to isolate them socially.

Less visible disabilities are also associated with lower rates of disclosure and access to disability services and accommodations, and this appears to be related to the problem of stigma. Research by Mullins and Preyde (2013) involved interviews with university students with hidden disabilitiesdyslexia, attention deficit hyperactivity disorder, and mental illness. Students identified a number of social and organizational barriers that discouraged disclosure of their disabilities and encouraged shame and embarrassment at having a disability and seeking accommodations for it. These included resistance from professors, resentment from other students, and wider public perceptions around their less visible disability $(2013$, p. 154). The invisible nature of students' disabilities had a role in the negative perceptions surrounding them.

Essentially, the decision whether to disclose a disability hinges on a number of factors - its visibility, which gives individuals more or less of an option to keep their disability "hidden", fears of stigma, discrimination, and differential treatment, admission to oneself of having a disability and/or needing accommodations and differential treatment, and the utility and outcomes of disclosing. Students are less likely to disclose their disability(ies) when:

1. the disability is concealable,

2. the environment is hostile or is perceived as hostile towards disclosure,

3. the admission that accommodations or differential treatment are required is confronting, and

4. the outcomes of disclosure are unclear or seen to be ineffectual.

\section{Indigenous disclosure}

Since the publication of the landmark report, A Fair Chance for All in 1991, there has been increasing recognition of the importance of making Australian culture inclusive of Indigenous culture and practice (McKenna, 2014). For this change to be more than mere tokenism, it is essential that Indigenous people gain access to the same opportunities as the wider population. However, the proportion of Indigenous people who participate in higher education is believed to be less than half that of non-Indigenous Australians (Anderson et al., 2008). The reasons for this are unclear; however, some research suggests that the under-representation of Indigenous peoples in Australia's tertiary sector is related to a narrow and restrictive definition of Indigeneity, the orientation of Australian universities towards Eurocentric models of education and learning rather than models that recognise the needs and values of Indigenous communities, and perceptions of stigma and benefits related to disclosing Indigenous identity (Bat, Kilgariff, \& Doe, 2015; DiGregorio et al., 2000; Fogarty \& Schwab, 2012; Kinnane, Wilks, Wilson, Hughes, \& Thomas, 2014). Underrepresentation may also reflect the educational experience and aspirations of Indigenous students or lack of family support throughout their school careers (Craven, Tucker, Munns, Hinkley, \& Simpson, 2005).

This underrepresentation may be attributable to structural factors within the university such as inappropriate orientation, stress or negative reactions to "special treatment" from other students. Farrington et al. (1999) found that Indigenous students at the University of Sydney were tentative 
about pursuing tertiary study before enrolling. This reluctance was related to perceptions that university study was too difficult and out of reach, doubts about their own abilities, stigma associated with gaining entry through an alternative pathway, and distance from home and family. However, these students also reported greater satisfaction and more interest in continuing study when accessing an equity service - the Cadigal Program. Thus, Indigenous students face stigma and self-doubt when entering university; however, disclosure to equity services is also associated with better support and self-reports of satisfaction with the level of support (Farrington et al., 1999).

Challenging these findings, Foundation Chair of Australian Indigenous Studies at the University of Melbourne, Professor Marcia Langton, argues that such accommodations are a double-edged sword, calling them a "huge weakness"; "it is too easy for Aboriginal people to retreat into the comfort zone of an enclave rather than regarding high achievement and excellence as the goal" (Trounson, 2011).

The Australian Bureau of Statistics (ABS, 2012) study consulted Indigenous focus groups and identified several reasons to self-disclose as Indigenous. Paraphrased, these were:

1. Pride and confidence in their identity

2. Perceived benefits for Aboriginal and Torres Strait Islander peoples and the individual personally

3. Desire for recognition of issues related to Aboriginal and Torres Strait Islander peoples

4. A "Confirmation of Aboriginality" to support their identification

5. The perception that answering the question was compulsory

It is unclear which of these would extend to university students. Point 4 is a prerequisite rather than a benefit of disclosure in this context, and universities are not in a position to make disclosure compulsory. The information may benefit other students and the community, but students may differ in the responsibility they feel for this aspect. However, other benefits such as access to services may entice students to disclose.

Conversely, the reasons to avoid disclosure in the ABS study are:

1. Fear of negative repercussions for the individual/community

2. Fear of racism, discrimination or differential treatment

3. Learned behaviour owing to previous experiences

4. Offence at being asked the identity question

5. A need for more information about the reasons for asking questions.

These reasons seem applicable to the university context, and point to a lack of trust in the process of disclosure. Some of the research suggests that Indigenous students are more likely to disclose to access equity services, which appear to be well received by Indigenous students and associated with higher rates of performance, satisfaction and retention. However, this research also suggests that accessing these services and identifying as Indigenous to attain lower TER and ATAR thresholds are associated with discrimination and poor treatment by some non-Indigenous students. In addition, Langton suggests that these services may be harmful to student performance, as well as assisting Indigenous students in a new and often challenging environment (Trounson, 2011).

\section{Disclosure by students from non-English-speaking backgrounds}

Students from non-English-speaking backgrounds (NESB students) face significant challenges in 
Australia's tertiary education system. These students operate in an environment where advanced English skills are often considered standard, and where accessing essential support and services often depends on an ability to understand, navigate and utilise English speaking, reading, and writing skills. Despite these challenges, Australia's tertiary student population in 2015 included 40,281 domestic NESB students, in a total student population of 1,035,474 students. These figures are distinct from Australia's international student population, which is not considered in this study, but is nevertheless far greater (134,163 students in 2015) (Department of Education and Training, 2016).

Traditionally, considerations of NESB students have assumed these students to be international students. However, recent research has focused on a more nuanced understanding of NESB status. These students are culturally and linguistically diverse (CALD), and in many cases are Australian citizens or long-term residents. Nevertheless, NESB students from domestic backgrounds have previously been identified as often failing to meet professional standards of English (Birrell, 2006) and may experience discrimination or exclusion as they negotiate identities at the intersection of Australian norms and customs and those of their own backgrounds. In essence, NESB and CALD individuals are local students, but share many of the same insecurities and challenges as migrants, albeit in an environment where "migrant" is a fixed and restrictive term that many do not identify with. Some of these individuals are second-generation refugees (Joyce et al., 2010; Kong et al., 2016); others are students who have come from overseas and attained citizenship before going on to tertiary study (Fildes, Cunnington, \& Quaglio, 2010). Hence, NESB students are a diverse group with some similar and many differing needs.

Fildes et al. (2010) identify a number of factors weighing on the mental health and performance of NESB students in Australian universities. These included academic barriers, such as not knowing "the system". Several students were unaware that they were able to request extensions, or were unaware of online course components or university email accounts. Essentially, they lacked understanding of the structures the university offers them. Second, there are language and cultural barriers. Students had issues with formal and informal language, vocabulary and terminology. Related to this, asking questions of tutors, lecturers, and other staff was complicated by anxiety surrounding their poor self-perceptions of their language skills (2010, pp. 30-31). Students faced social barriers related to isolation and in many cases having few family members and friends nearby to talk to, or who understood their issues at university. Personal barriers such as disconnection from mainstream cultural norms, and a sense of disconnection from the wider community also affected NESB student wellbeing (2010, p. 32). Most importantly, structural barriers were found to create a rift between NESB students and university educators.

From the perspective of university teaching and academic staff, NESB and CALD students are perceived to be difficult and as taking up time and resources. Many tertiary educators feel challenged by NESB students and may not consider themselves qualified to support the students' linguistic and cultural needs. They may become frustrated by grammatical mistakes or inappropriate styles of writing, and by the extra time required to correct them (Pantelides, 1999). Ballard and Clanchy (1997, p. 2) found that lecturers were often frustrated by perceived "weaknesses" and "poor English" among students and "the extra demands that fall upon them as teachers". This may cause ambivalence about the benefits of internationalisation in higher education. Teaching staff are at the interface of these ideologies, and may experience some dissonance about their roles and responsibilities" (Fildes et al., 2010, p. 26).

Although there is little research on NESB disclosure/nondisclosure at this point in time, the research suggests that NESB students face real and perceived barriers in accessing services and seeking help in universities. This may be due to a lack of services in the university related to language skills, a lack of awareness of those services, or a disconnection from the wider student population. This may 
also be due to cultural barriers that may make many NESB students uncomfortable seeking help or see asking for help or assistance in the form of accommodations or extensions as embarrassing or as a personal defeat. As discussed by Fildes et al. (2010), cultural and linguistic differences do not exist in isolation, and extend a rift between NESB students and teaching staff. This may also make students apprehensive to approach staff for help when they need it.

\section{Disclosure/conclusion}

Discussions of disability disclosure have generally focused on disclosure by students and employees to institutions and supervisors. The literature concerns disclosure of Indigenous status to institutions both in Australia and globally, while that of NESB relates to access to and support from equity services. These groups are distinct in form; the first is based on physical and nonphysical limitations, the second is an ethnic group, and the third is a language group, often with overlapping issues of ethnicity and migration. However, these groups approach self-disclosure with broadly similar considerations: fear of stigma and differential treatment, an admission to oneself that help is needed or that an equity status affects wellbeing and performance, and considerations of what the individual will actually receive - the outcomes of self-disclosure. This study aims to estimate the true numbers of non-disclosing equity students in Australia's tertiary sector, and to shed light on these and other considerations. However, this presents major methodological challenges, as this study focuses on a hidden population, and involves considerations of specific needs and vulnerabilities, while respecting students' choice to remain hidden.

\section{Methodology}

Approaching nondisclosure presents a significant challenge to researchers. Non-disclosing equity students are, by definition, largely undocumented and unknown to equity services. Their disability(ies), Indigenous status, and/or language background are unknown; hence, they are invisible for statistics and research purposes. Essentially, nondisclosing students are a hidden population, often by choice. Because of this, finding research subjects is a challenge in itself.

University staff were surveyed across campuses Australia-wide. Participants were recruited through emailing equity services based at Australian universities, and through snowball sampling respondents. The purpose of this survey was to gauge frontline staff understandings of the equity student experience. Because of this, equity service practitioners were specifically targeted for the survey. The staff survey concerns perceptions of equity numbers and representation at the university. The purpose of this survey was to identify staff perspectives of how many equity students were present at the institution, and the quality of the services offered to these students. This is important because divergence between staff perspectives of equity numbers and services and student perspectives indicate a critical gap in service delivery and/or information sharing between staff and students. Staff surveys were distributed to university staff through personal contacts of the researchers, mailing lists, institutional emails and cold calling (through email) university equity services at various university campuses across Australia. Equity unit email addresses were gathered from websites, and although not all responded, all 39 universities were sent an email with a description of the project and a link to the survey.

Ethics approval was granted by the University of New South Wales' (UNSW) Higher Research Ethics Committee on April 5, 2017.

This research approached this problem through a mixed-methodology model, employing quantitative and qualitative methods. Our methodology included online surveys of staff and students regarding their own equity status and their perceptions of equity numbers. Through deidentified surveys, participants could offer their personal information and equity data safely, without fear of unwanted 
further contact or being fitted into a rigid and static equity box from which they may later wish to withdraw. These surveys also offered space for staff and students to express their own opinions on equity disclosure/nondisclosure; thus, they were emancipatory in nature.

\section{A staged approach}

This research consisted of three stages. Stage one was a staff survey concerning perceptions of equity numbers and representation at the university. The purpose of this survey was to identify staff perspectives on the accuracy of estimates of equity students at their institutions and the quality of the services offered to these students. This is also important, because divergence between staff perspectives of equity numbers and services and student perspectives indicate a critical gap in service delivery and/or information sharing between staff and students. Staff surveys were distributed to university staff through personal contacts of the researchers, mailing lists, institutional emails and cold calling (through email) university equity services to all university campuses across Australia. Sponsored Facebook posts were also employed.

The second stage was a survey of students, conducted in mid-2017 distributed to all 39 universities in Australia via staff contacts and Facebook posts. The third stage consisted of focus groups and interviews with students and staff, scheduled to occur in late 2017. At the time of writing this paper, only the data from the staff survey had been collected and analysed. Therefore this paper reports on the first stage only (staff survey) with further reporting planned to occur once data from the second and third stages have been collated and analysed.

The Third stage involved face-to-face or over-the-phone interviews to follow up and expand on the findings of the survey. Students opted-in to be interviewed by ticking a box and providing their contact details at the end of the survey. Essentially, surveys offered a wide selection of data on a national scale, while interviews offered a chance to follow up on trends identified in the surveys indepth and consider personal experiences with equity disclosure.

\section{Results}

At the time of writing, 216 staff members from 27 universities, including 11 regional universities, seven 'Group of Eight' universities and nine other metropolitan universities, had clicked on the email link to the staff survey. Of these 216 staff members, 87 provided substantive responses-a $40 \%$ response rate. These responses are divided between the three areas of equity-staff may manage equity for Indigenous students, students with disabilities, NESB students or a combination.

\section{Indigenous students}

Responses to the first question, "What is the role of disclosure of Indigenous heritage at your university (i.e. is it necessary to access services, support or facilities?)", indicated that disclosure of Aboriginality was required by all universities for access to services, scholarships or targeted support, and most required confirmation. All the universities that responded to this section offered students the opportunity to disclose to a dedicated Indigenous service at or following enrolment, as well as pathways to do so with administrative services thereafter. Of 33 respondents to that question, 19 expressed the view that the true number of Indigenous students is higher than the number that disclose this, while only three believed the reported number to be accurate. One respondent noted that some students check the box on the enrolment form but do not have documentation. On the other hand, a former staff member of the Indigenous unit of a metropolitan university stated that many of those who click the "Indigenous" box when registering with a tertiary admissions centre do so accidentally or do not understand the term.

The staff responses indicated that they considered the two most common reasons for nondisclosure 
to be: a disinclination to be labelled (9/10 respondents); and fear of prejudice in university life (8/10). See Table 1 below.

Other staff comments refer to difficulties that students encounter in proving Indigenous heritage, with some students (particularly those who do not feel that their appearance or background conform to common stereotypes of Indigenous people) feeling that they do not have the right to identify; also perceptions by students that the universities' anxiety to identify Indigenous students was to gain funding or to improve their public image rather than help students. For example, Participant 43 states: "I was concerned about the stigma around it and then once you get over the stigma, well like forgive me, but you're not 'black' enough. And then you... I don't know, how do you respond to that? When people just saying I don't believe you, well why would I lie about it? And ... what benefit do I get from saying this? Nothing!"

Table 1: Staff perceptions of reasons for nondisclosure by Indigenous students

\begin{tabular}{ll}
\hline Reasons for Nondisclosure & Response Count \\
\hline They do not trust the university with this information & 7 \\
They see no benefit in disclosure & 30 \\
They fear prejudice in their university life & 12 \\
They fear prejudice in their professional life after & 18 \\
university & 32 \\
They are concerned about confidentiality & 18 \\
They do not wish to be "labelled" & 12 \\
They do not believe the university needs to know & 16 \\
They do not know how to disclose & 11 \\
They do not have the necessary documentation & 18 \\
Other (please specify) &
\end{tabular}

34 Respondents

Comments include:

- We have had a couple of students who have chosen not to disclose because of a perception of using their identity to take advantage in the competitive space of scholarship selection.

- I believe that students may not wish to disclose their heritage or be identified to non-Indigenous staff

- Some students don't disclose due to cultural safety issues

- To access services ... it is necessary that students have a Confirmation of Aboriginality. Many students that are Aboriginal and/or Torres Strait Islanders may not have access to this or the knowledge of where their 'mob' comes from so they do not disclose.

Measures to encourage disclosure include advertised encouragement and reassurances of confidentiality and cultural safety. One large NSW regional university has previously offered "... an excellent camp where the students would go to Canberra for a camp and track their family tree". Respondents were generally unsure about the effectiveness of these measures, although the Canberra camp was described as "very effective".

From both staff and student comments, it appeared to be essential that the benefits of disclosure are explained, and that universities avoid giving the impression that Indigenous students are viewed as $a$ priori less capable or in need of special treatment. 


\section{Students with disabilities}

For students with disabilities, there was less unanimity with regard to the need for disclosure. Most respondents stated that that disclosure and documentation was necessary to access support, but one respondent (from a regional Queensland university) stated "[disclosure] is highly encouraged, but access is not limited to disclosure". Another important point is made by a respondent from a regional NSW university, who notes "We try to also provide an inclusive environment, where adjustments (and disclosure) aren't required".

\section{Reasons for nondisclosure}

The question on reasons for disclosure was subdivided according to type of disabilities. The six categories shown in Table 2 are those used by the Education Council Joint Working Group to provide Advice on Reform for Students with Disability (Education Council 2017): physical, cognitive, sensory, and social/emotional. There is an additional category for carers. ${ }^{1}$

Fear of prejudice and a desire to avoid labelling were among the strongest reasons for nondisclosure in the view of respondents. However, a lack of knowledge about how to disclose and concerns about confidentiality were also seen as strong disincentives to disclose, the latter particularly evident when referring to those with social/emotional disabilities. If the respondents are correct, the disincentives are particularly strong for those with cognitive as well as social/emotional disabilities, perhaps because these are less likely to be obvious than physical or sensory issues. All institutions had dedicated disabilities support services.

Methods to encourage disclosure included direct advertising of services via leaflets and central portals, promotion during orientation: "Promotion, referral services, awareness amongst academic staff, embedded in orientation, outreach activities to partner schools, widening participation activities targeting SWDs" (regional Victorian university correspondent).

Table 2 shows staff responses to the question, "From your experience, why might students be reluctant to self-disclose a disability?" These show differences between disability types, with confidentiality and trust issues being scored highly for those with cognitive or social/emotional issues. The scores are lower for those with physical disabilities, perhaps because these tend to be less easily concealable.

There was a range of responses to the question on the effectiveness of these measures. The measures considered effective were described as follows:

- Students are encouraged to disclose to disability services by information provided in handbooks, orientation, early lectures and periodically to students and staff. Most students are referred to disability services from other staff (academic and other student services) after they disclose to them, and in response to relevant special consideration applications.

- There are standard approaches all universities apply but students who are happy to disclose and seek early notification and those who tend to delay will always delay.

\footnotetext{
${ }^{1}$ A description of the disabilities in these categories may be found here: http://www.schooldisabilitydatapl.edu.au/docs/defaultsource/default-document-library/broad-categories-of-disability.pdf
} 
Table 2: Staff perceptions of reasons for nondisclosure by students with disabilities

\begin{tabular}{|c|c|c|c|c|c|c|}
\hline Answer Options & $\begin{array}{l}\text { Students } \\
\text { with } \\
\text { physical } \\
\text { disabilities }\end{array}$ & $\begin{array}{l}\text { Students } \\
\text { with } \\
\text { cognitive } \\
\text { disabilities }\end{array}$ & $\begin{array}{l}\text { Students } \\
\text { with } \\
\text { sensory } \\
\text { disabilities }\end{array}$ & $\begin{array}{l}\text { Students with } \\
\text { social / } \\
\text { emotional } \\
\text { disabilities }\end{array}$ & $\begin{array}{l}\text { Student } \\
\text { carers for } \\
\text { people } \\
\text { with a } \\
\text { disability }\end{array}$ & $\begin{array}{l}\text { Response } \\
\text { Count }\end{array}$ \\
\hline $\begin{array}{l}\text { They do not trust the } \\
\text { university with this } \\
\text { information }\end{array}$ & $\begin{array}{c}50 \% \\
14\end{array}$ & $\begin{array}{c}68 \% \\
19\end{array}$ & $\begin{array}{c}46 \% \\
13\end{array}$ & $\begin{array}{c}89 \% \\
25\end{array}$ & $\begin{array}{c}43 \% \\
12\end{array}$ & 28 \\
\hline $\begin{array}{l}\text { They see no benefit } \\
\text { in disclosure }\end{array}$ & $\begin{array}{c}42 \% \\
11\end{array}$ & $\begin{array}{c}42 \% \\
11\end{array}$ & $\begin{array}{c}31 \% \\
8\end{array}$ & $\begin{array}{c}58 \% \\
15\end{array}$ & $\begin{array}{c}65 \% \\
17\end{array}$ & 26 \\
\hline $\begin{array}{l}\text { They fear prejudice } \\
\text { in their university } \\
\text { life }\end{array}$ & $\begin{array}{c}59 \% \\
22\end{array}$ & $\begin{array}{c}78 \% \\
29\end{array}$ & $\begin{array}{c}57 \% \\
21\end{array}$ & $\begin{array}{c}92 \% \\
34\end{array}$ & $\begin{array}{c}43 \% \\
16\end{array}$ & 37 \\
\hline $\begin{array}{l}\text { They fear prejudice } \\
\text { in their professional } \\
\text { life after university }\end{array}$ & $\begin{array}{c}57 \% \\
16\end{array}$ & $\begin{array}{c}82 \% \\
23\end{array}$ & $\begin{array}{c}68 \% \\
19\end{array}$ & $\begin{array}{c}89 \% \\
25\end{array}$ & $\begin{array}{c}50 \% \\
14\end{array}$ & 28 \\
\hline $\begin{array}{l}\text { They are concerned } \\
\text { about confidentiality }\end{array}$ & $\begin{array}{c}61 \% \\
19\end{array}$ & $\begin{array}{c}77 \% \\
24\end{array}$ & $\begin{array}{c}65 \% \\
20\end{array}$ & $\begin{array}{c}90 \% \\
28\end{array}$ & $\begin{array}{c}58 \% \\
18\end{array}$ & 31 \\
\hline $\begin{array}{l}\text { They do not wish to } \\
\text { be "labelled" }\end{array}$ & $\begin{array}{c}71 \% \\
27\end{array}$ & $\begin{array}{c}76 \% \\
29\end{array}$ & $\begin{array}{l}71 \% \\
27\end{array}$ & $\begin{array}{c}87 \% \\
33\end{array}$ & $\begin{array}{c}53 \% \\
20\end{array}$ & 38 \\
\hline $\begin{array}{l}\text { They do not believe } \\
\text { the university needs } \\
\text { to know }\end{array}$ & $\begin{array}{c}45 \% \\
13\end{array}$ & $\begin{array}{c}69 \% \\
20\end{array}$ & $\begin{array}{c}52 \% \\
15\end{array}$ & $\begin{array}{c}79 \% \\
23\end{array}$ & $\begin{array}{c}69 \% \\
20\end{array}$ & 29 \\
\hline $\begin{array}{l}\text { They do not know } \\
\text { how to disclose }\end{array}$ & $\begin{array}{c}52 \% \\
14\end{array}$ & $\begin{array}{c}96 \% \\
26\end{array}$ & $\begin{array}{c}67 \% \\
18\end{array}$ & $\begin{array}{c}89 \% \\
24\end{array}$ & $\begin{array}{c}81 \% \\
22\end{array}$ & 27 \\
\hline $\begin{array}{l}\text { No pathway exists to } \\
\text { disclose }\end{array}$ & $\begin{array}{c}33 \% \\
1\end{array}$ & $\begin{array}{c}33 \% \\
1\end{array}$ & $\begin{array}{c}33 \% \\
1\end{array}$ & $\begin{array}{c}33 \% \\
1\end{array}$ & $\begin{array}{c}100 \% \\
3\end{array}$ & 3 \\
\hline answered question & & & & & & 43 \\
\hline
\end{tabular}

Finally, it should be noted that most respondents $(75 \%)$ agreed that official figures underreport the true number of students with disabilities. Comments note differences in reporting (for example, whether international students or those registered with pathway providers on campus are included). Students may not recognise their condition as a disability, or they fear repercussions. One respondent noted "I am not sure that we want numbers to rise-it would be much better if students were just included!"

\section{NESB Students}

Non-English-speaking background (NESB) is the most problematic area regarding nondisclosure, because in many cases there is no pathway for disclosure beyond listing a first language other than English on the enrolment form or seeking help (for which disclosure is not required). Moreover, if students speak English with native or near-native fluency they do not require language support. Of 24 respondents, 14 believed the reported number of NESB students to be an underestimate; six did not know and three believed the number to be accurate. The primary method of disclosure for NESB students is considered to be registration with a dedicated language support service with other support services or equity services also available. 
A respondent from a Queensland metropolitan university noted:

The university derives this information via the government formula-definition provided below. If the first character of the "Year of Arrival" field is not A; and the difference between the submission year and the year of arrival is less than 10; and the Year of Arrival is $<=9999$, and the Language code if between 1000 and 9799 (inclusive) or language code $=9998$ THEN The NESB Indicator is set to Y, otherwise its set to N. Our domestic students are able to access our Academic Language and Learning Services team for support

Table 3 shows the reasons proposed for nondisclosure. Labelling is again the largest category, but perhaps predictably when disclosure is not necessary to access services, "they see no benefit in disclosure" was also common (the student survey also indicates that nearly $75 \%$ of domestic NESB students consider their English proficiency to be equal to that of a native speaker). Responses in the comments section included, "Goes against their culture to admit they have something wrong" and "they don't necessarily see it as an issue".

Table 3: Staff perceptions of reasons for nondisclosure by NESB students

\begin{tabular}{lcc}
\hline $\begin{array}{l}\text { From your experience, why might students be reluctant to disclose a non-English speaking } \\
\text { background? }\end{array}$ & $\begin{array}{c}\text { Response } \\
\text { Percent }\end{array}$ & $\begin{array}{c}\text { Response } \\
\text { Count }\end{array}$ \\
$\begin{array}{l}\text { Answer Options } \\
\text { They do not trust the university with this information }\end{array}$ & $32 \%$ & 7 \\
They see no benefit in disclosure & $68 \%$ & 15 \\
They fear prejudice in their university life & $68 \%$ & 7 \\
They fear prejudice in their professional life after university & $32 \%$ & 16 \\
They are concerned about confidentiality & $27 \%$ & 11 \\
They do not wish to be "labelled" & $73 \%$ & 12 \\
They do not believe the university needs to know & $50 \%$ & 7 \\
They do not know how to disclose & $55 \%$ & 5 \\
No pathway exists for disclosure & $32 \%$ & 22 \\
\hline
\end{tabular}

Overall, in the opinion of the staff respondents, the main reasons for nondisclosure centre on fear of prejudice (from staff or other students) and a disinclination to be seen as "special" or as a member of a potentially stigmatised group. Moreover, there were concerns about the way in which such information may be interpreted or used by the university or whether disclosing this information would benefit the student concerned.

University staff members who offer support indicated in their responses that disclosure concerns issues of identity in addition to needs. The decision to disclose may reflect students' experiences of and relationship to bureaucracy, and may reflect a rejection of labels such as "disadvantaged". 


\section{Discussion/conclusion}

A student's decision to disclose their equity status involves myriad considerations that are personally, temporally, and culturally determined. Non-disclosing students form a disaggregated collective that is both invisible to service providers and to other nondisclosing students as well. This presents significant challenges for researchers and practitioners alike. Nevertheless, common themes continue to appear in disclosure considerations. Some of these are more equity-group specific than others, such as fears of stigma among those with hidden disabilities and indigenous students, but less relevant for students from non-English speaking backgrounds for whom their status is either not important in some cases, or plainly obvious in others. Three themes are recurrent in self-reporting of nondisclosure considerations: stigma, self-image and self-esteem, and the utility of disclosure.

\section{Limitations and future research}

This research project examined the perceptions and opinions of staff in university equity units across Australia. However, at the time of writing, the number of staff members who have responded remains limited, and there remains scope for a follow up study of practices to improve disclosure at universities.

In future research, we intend to balance staff perceptions with student surveys to assess the success of inclusion practices and measures to encourage self-disclosure of equity group membership at university from the recipients' perspective. These survey findings will be bolstered by interviews with focus groups and individual students to provide rich qualitative data on their experiences and understanding of self-disclosure issues.

Finally, there remains work to be undertaken with respect to implicit definitions and models of disability held by university students and staff. Medical models of disability often result in a "deficit model" whereby student disabilities are seen as problems rather than as part of the diverse range of needs, and this may have implications for their inclusion.

\section{Acknowledgements}

The authors wish to thank the UNSW Sydney Student Life staff who have contributed to this paper: Julian Barber, Jessie Lui, Jessica Luquin, Helen Meas, Jeffrey Meesterman and Alison Rueli See. 


\section{References}

Bandias, S., Fuller, D., \& Larkin, S. (2014). Indigenous students in the tertiary education sector. Journal of International Education Research, 10(3), 179-200. http://dx.doi.org/10.19030/jier.v10i3.8738

Bat, M., Kilgariff, C., \& Doe, T. (2015). Higher education research \& development Indigenous tertiary education-we are all learning: Both-ways pedagogy in the Northern Territory of Australia. Higher Education Research \& Development, O(0), 1-16. https://doi.org/10.1080/07294360.2014.890575

Birrell, B. (2006). Implications of low English standards among overseas students at Australian universities. People and Place 14(4), 53-64.

Bulk, L. (2014). Disability disclosure : Thoughts from a student. Occupational Therapy Now, 17(6), 18-20.

Chirgwin, S. (2015). Burdens to difficult to carry? A case study of three academically able Indigenous Australian masters students who had to withdraw. International Journal of Qualitative Studies in Education, 28(5), 594-609. https://doi.org/10.1080/09518398.2014.916014

Cox, B. E., Thompson, K., Anderson, A., Mintz, A., Locks, T., Morgan, L., Edelstein, J. \& Wolz, A. (2017). College experiences for students with autism spectrum disorder: personal identity, public disclosure, and institutional support. Journal of College Student Development, 58(1), 71-87. https://doi.org/10.1353/csd.2017.0004

Department of Education and Training (2016). 2015 Appendix 2-Equity groups. Australian Government Department of Education and Training. Retrieved from https://docs.education.gov.au/node/41746 21/6/2017.

DiGregorio, K. D., Farrington, S., \& Page, S. (2000). Listening to our students: understanding the factors that affect Aboriginal and Torres Strait Islander students' academic success. Higher Education Research \& Development, 19, 297-309. https://doi.org/10.1080/758484344

Earnest, J., Joyce, A., de Mori, G., \& Silvagni, G. (2010). Are universities responding to the needs of students from refugee backgrounds? Australian Journal of Education, 54(2), 155-174. https://doi.org/10.1177/000494411005400204

Education Council (2017). Nationally consistent collection of data. 2016 emergent data on students in Australian schools receiving adjustments for disability. Retrieved from

http://www.educationcouncil.edu.au/site/DefaultSite/filesystem/documents/Reports\%20and\%20publi cations/ED17-0046\%20SCH\%20NCCD\%20Report\%202017_ACC.PDF on 5/4/2017.

Farrington, S., \& Daniel DiGregorio, K. (1999). The things that matter: Understanding the factors that affect the participation and retention of indigenous students in the Cadigal Program at the Faculty of Health Sciences, University of Sydney, 1999 Annual Conference of The Australian Association for Research in Education Melbourne, 1999. Retrieved 23/6/2017 from https://eric.ed.gov/?id=ED447977.

Fildes, L., Cunnington, C., \& Quaglio, M. (2010). Staying the course : The importance of social and structural networks for NESB students achieving positive outcomes at a regional campus. Journal of Academic Language and Learning, 4(1), A24-A40.

Fogarty, W., \& Schwab, R. G. (2012). Indigenous education: Experiential learning and learning through country. Working Paper 80/2012, Centre for Aboriginal Economic Policy Research, ANU College of Arts \& Social Sciences. Retrieved 20/6/2017from http://caepr.anu.edu.au/Publications/WP/2012WP80.php

Hannah, J. (1999). Refugee students at college and university: Improving access and support. International Review of Education, 45(2), 153-166.

Hartman-Hall, H. M., \& Haaga, D. A. F. (2002). College students' willingness to seek help for their learning disabilities. Learning Disability Quarterly, 25, 263-274.

Hernandez, M. (2011). People with apparent and non-apparent physical disabilities: well-being, acceptance, disclosure and stigma. Ph.D. thesis, San Diego California: Alliant International University.

Hoehn, S. C. (1998). Relationships between self-perception of disability and help-seeking behaviours of postsecondary students with learning disabilities. Los Angeles, University of California.

Jacklin, A. (2011). To be or not to be "a disabled student" in higher education: The case of a postgraduate "non-declaring" (disabled) student. Journal of Research in Special Educational Needs, 11(2), 99-106. https://doi.org/10.1111/j.1471-3802.2010.01157.x

Joyce, A., Earnest, J., de Mori, G., \& Silvagni, G. (2010). The experiences of students from refugee backgrounds at universities in Australia: Reflections on the social, emotional and practical challenges. Journal of Refugee Studies, 23(1), 82-97. https://doi.org/10.1093/jrs/feq001 
Kinnane, S., Wilks, J., Wilson, K., Hughes, T., \& Thomas, S. (2014). “Can't be what you can't see”: The transition of Aboriginal and Torres Strait Islander students into higher education. Broome: The University of Notre Dame, Australia. Retrieved 23/6/2017 from http://www.nd.edu.au/_data/assets/pdf_file/0018/122364/OLT-ID-SI112138-Lit-Rev-Final-14-March-2014.pdf

Kong, E., Harmsworth, S., Rajaeian, M. M., Parkes, G., Bishop, S., AlMansouri, B., \& Lawrence, J. (2016). University transition challenges for first year domestic CALD students from refugee backgrounds: A case study from an Australian regional university. Australian Journal of Adult Learning, 56(2), 170-197.

Kreider, C. M., Bendixen, R. M., \& Lutz, B. J. (2015). Holistic needs of university students with invisible disabilities: A qualitative study. Physical \& Occupational Therapy in Pediatrics, 35(4), $426-441$. https://doi.org/10.3109/01942638.2015.1020407

Mathews, C. K., \& Harrington, N. G. (2000). 'Invisible Disability', In D. O. Braithwaite \& T. L. Thompson (Eds.), Handbook of communication with people with disabilities (pp. 405-421). N.J.: Lawrence Erlbaum Associates Inc.

Morris, D., \& Turnbull, P. (2006). Clinical experiences of students with dyslexia. Journal of Advanced Nursing, 54(2), 238-247.

Mullins, L., \& Preyde, M. (2013). The lived experience of students with an invisible disability at a Canadian university. Disability \& Society, 28(2), 147-160. https://doi.org/10.1080/09687599.2012.752127

Olney, M. F., \& Brockelman, K. F. (2003). Out of the disability closet: Strategic use of perception management by select university students with disabilities. Disability \& Society, 18(1), 35-50. https://doi.org/10.1080/713662200

Riley, G. A., \& Hagger, B. F. (2015). Disclosure of a stigmatized identity: A qualitative study of the reasons why people choose to tell or not tell others about their traumatic brain injury. Brain Injury, 29(12), 1480-1489. https://doi.org/10.3109/02699052.2015.1071427

Rochecouste, J., Oliver, R., Bennell, D., Anderson, R., Cooper, I., \& Forrest, S. (2016). Teaching Australian Aboriginal higher education students: What should universities do? Studies in Higher Education, 5079, 1-19. https://doi.org/10.1080/03075079.2015.1134474

Rosenthal, D. A., Efklides, A., \& Demetriou, A. (1988). Parental criticism and young adolescent self-disclosure: A crosscultural study. Journal of Youth and Adolescence, 17(1), 25-39. https://doi.org/10.1007/BF01538722

Sung, C., Lin, C.-C., Connor, A., \& Chan, F. (2017). Disclose or not? Effect of impression management tactics on hireability of persons with epilepsy. Epilepsia, 58(1), 128-136. https://doi.org/10.1111/epi.13619

Trounson, A. (2011, April 20). Support centres can hold back indigenous students. The Australian. Retrieved from http://www.theaustralian.com.au/higher-education/support-centres-can-hold-back-indigenous-students/news-st ory/b4db717d94dcc9208f8c53d0679f2e30

\section{The authors may be contacted via:}

c.clark@unsw.edu.au

\section{Please cite this paper as:}

Clark, C., Kusevkis-Hayes, R. \& Wilkinson, M. (2018). Enhancing student disclosure: Australia's invisible equity students and reasons for nondisclosure in Australia's tertiary sector. Journal of the Australian and New Zealand Student Services Association, (26)1, 28-41. https://doi.org.10.30688/janzssa.2018.05 